\title{
The status of twenty-first century skills within the University of Milan-Bicocca's Degree Programme in Primary Education
}

\author{
Lilia Andrea Teruggi, Franca Zuccoli
}

\begin{abstract}
This paper describes the extent to which $21^{\text {st }}$ Century Skills are provided for in both teacher training curriculum documents and educational practices (courses, workshops and teaching practice) in the context of the Degree Course in Primary Education offered by the University of Milan-Bicocca. Our observations are based on a diachronic analysis of the degree course from its introduction in 1999 up to the most recent education reforms. We also assess the extent to which these skills feature in the National Curricular Guidelines for Primary Education. Although twenty-first century skills are not explicitly referred to in the third level curriculum documents, they are implicitly well represented in the key transversal themes running through the five-year degree programme; while they receive clear and specific mention in the ministerial guideline documents.
\end{abstract}

Key words: $21^{\text {st }}$ Century Skills; Teacher Training; National Curricula. 


\section{Introduction}

It is critical to make provision for the development of twenty-first century skills, insofar as education is continuously required to adjust to broader societal changes. We must prepare our students to face these changes, which affect the cultural, economic, and domestic spheres. The skills demanded by twenty-first century society encompass affective and aesthetic as well as cognitive abilities, and cater for the needs of both individual children and society as a whole. It follows that examining how these competences are viewed and promoted in teacher training courses and in teacher practices in schools, is particularly relevant to assessing how our country is educating its future citizens.

In order to put the Italian situation into context, we first briefly outline the history of teacher training in recent years, in particular at our own university of Milan-Bicocca. In 1999, Italy introduced a new Degree in Primary Education, which then became the only recognized qualification for infant school (3-6 years) and primary school (6-10 years) teachers. This was the translation into practice of the proposal, which had been debated for decades, to provide university-level training as opposed to high-school programmes for future teachers, through the development of ad hoc undergraduate courses.

The decision to provide such a new course of studies at the University of Milan-Bicocca originated within the Department of Educational Human Sciences, at the initiative of a group of professors in the areas of history, philosophy, education and the human and natural sciences, whose aim was to promote the interdisciplinary study of educational processes. From the outset, the degree programme was characterized by a strong emphasis on research in educational contexts, with the development and refinement of methods and instruments for field observation and for managing communication among the various social actors involved in the school system (pupils, parents, teachers, and other stakeholders) (Teruggi \& Bettinelli, 2010).

The group that set up the degree programme shared a vision of teachers as reflective practitioners (Schön, 2006) who reflect on and during their practice, in order to address the ever-changing challenges posed by their profession. The competences that trainee teachers were expected to develop included: holding up-to-date knowledge and being able to metacognitively reflect on the process of acquiring it; having the ability to observe contexts and relationships in order to design meaningful educational interventions; knowing how to listen to and understand students with a view to managing communication with and among pupils, together with families; reflecting and sharing with colleagues about the work carried out; and recording and evaluating teaching and learning activities. For these objectives to be met, the course was designed to combine traditional modules, delivered using innovative teaching methods, with practical course work and workshops conducted with a small number of students (25-30), as well as periods of teaching practice in infant and primary schools. 
Again in 1999, a competitive selection process was held to recruit teachers and head teachers to cooperate with the University in designing and implementing the crucial teaching practice component of the degree programme. The role of these figures has been to ensure a close working relationship between the university and schools, supervise students' teaching practice and contribute to the creation of a network of schools across the local area. A key characteristic of the course has been the fact that it offers two different modes of teaching practice: direct and indirect. "Direct" teaching practice is carried out in schools, while "indirect" takes place at the university among groups of students and a supervisor. The latter mode may be thought of as a space for reflecting on what is happening at the practical level. This dimension of making the link between theory and practice has been the focus of a national research project ${ }^{1}$ that analysed supervisors' routine activities in order to define their professional profile (Laneve \& Pascolini, 2014).

In reflecting on the practices that make up and characterise the Degree Course in Primary Education, it is of key importance to emphasize the use of the workshop method. From the outset, a distinctive feature of the course has been the fact that many of its modules include workshops, which may be on either education or subjectrelated topics. The value of the workshops lies in their dynamic nature "... as cognitive, operational and relational experience among adults based on:

- collaborative learning in small and large groups;

- real-life tasks providing the opportunity to observe, experiment, compare, enquire, hypothesize, produce;

- critical interpretation and creative production;

- meta-reflection on the processes implemented; mainly procedural as opposed to declarative contents;

- a high level of interaction between lecturers and students" (Varani, 2014, p. 187).

Admission to the degree course is based on a national entrance test and the number of places is defined on an annual basis by the Education Ministry. Currently, MilanBicocca University has a total of approximately 1,800 students enrolled on the five-year programme.

Given our own direct involvement in the training of future teachers, and in answer to the challenge laid down by the VoiceS project, we enquired how our degree course addresses the need for twentieth-century skills, considered essential for the education of the future generations. In attempting to answer our research question, we also

The Universities involved in this study were Bari, Cattolica (Brescia), Macerata, Milan-Bicocca; Milan SILSIS, Naples, Padua-Verona, Palermo, Perugia, Turin.

Note that the research also included the SILSIS, that is to say, the postgraduate courses in education for secondary school teachers. 
analysed the Indicazioni Nazionali per la Scuola del Primo Ciclo (2012) ${ }^{2}$, given that there is a close relationship between the recommendations of the Education Ministry and the educational offering contained in the degree course. Therefore, the current article reviews both our degree programme and the national guidelines with a view to determining the extent to which they provide for the development of twenty-first century skills. To this end, we analysed the relevant university and ministerial documents, as well as interviewing key informants at the University of Milan-Bicocca.

\section{Methodology}

In order to study the phenomenon in context and respond to our research question: how do our teacher training curriculum and the Italian National Guidelines provide for the development of twenty-first century skills and competences for New Millennium Learners in the OECD, we chose a case study research strategy. This empirical approach allowed us to focus on "a bounded system", our university's teacher training course and the National Curriculum, which we examined, observed and described in order to identify their key components. Robert Stake (1995) describes this kind of case study as 'holistic', because by focusing on a given issue in a given context it is possible to capture the essentials of the case.

We used several different data sources (Yin 2009): internal university documentation (current syllabus for the degree course), scientific publications, interviews with key informants, official documents issued by the Ministry of Education.

All written documents and interview transcripts were analysed following constructed categories or themes that became the category system. As Mayring (2002, 114) explains, "by using this category system, the aspects, which are to be filtered from the material, are defined". In our study, the aspects to be filtered from the collected data were fragments of text related to twenty-first century skills, that is to say, we combed our data for all references to these particular competences. We then carried out a comparative analysis, with the aim of identifying similarities and differences among the data sources (Bassey, 1999), in particular between our university teacher training course and the national curricular guidelines.

In this kind of approach to analyzing documents, the investigator's role in constructing the meaning of the text is predictable. Therefore, we drew on two different perspectives (triangulation) from within the university degree course. Triangulating the data is a means of clarifying the meaning of the context in which the category under analysis occurs (Bryman, 2004). In this way, we gained a fuller picture of how the Milan-

2 The reference here is to the national guidelines for the infant-primary and junior high school curricula issued in 2012. 
Bicocca teacher training course compared to the National Curriculum in relation to the skills required for the new millenium.

As stated above, the categories chosen were based on twenty-first century skills, in particular the following: Critical Thinking and Problem Solving, Collaboration Across Networks and Leading by Influence, Assessing and Analyzing Information, Effective Oral and Written Communication, Agility and Adaptability, Initiative and Entrepreneurialism, Curiosity and Imagination.

\subsection{Data analysis}

Twenty-first century skills in the National Guidelines

A highly innovative aspect of the national guideline document is the fact that the curricula for the various levels of schooling are centred around competences. By the end of infant, primary and lower secondary school (11-14 years) cycles, students are expected to have developed given sets of competences related to both fields of experience and specific school subjects. These objectives provide teachers with a clear reference framework, suggesting the type of cultural and teaching programmes to be implemented and helping to focus educational action on the student's holistic development. Many of the competences identified in the document are transversal as opposed to subject related; in particular, it is stated that all subject-specific learning programmes must contribute to the development of the key competences required for lifelong learning defined by the European Parliament and Council (Recommendation of 18 December 2006). These last-mentioned competences are the outcome of a major scientific and cultural debate in which Italy played an active part. They overlap significantly with the skills included in our analytical categories, as the following examples show:

Effective Oral and Written Communication, is divided into two sub-competences: communication in the mother tongue, which is the ability to express and interpret concepts, thoughts, feelings, facts and opinions in both oral and written form (listening, speaking, reading and writing) and to interact linguistically in an appropriate and creative way in a full range of societal and cultural contexts, including education and training, work, home and leisure settings; and communication in foreign languages, which also includes skills such as mediation and intercultural understanding.

Collaboration Across Networks and Leading by Influence, is partly reflected in the objective of digital competence, which involves the confident and critical use of information society technology (IST) for work, free time and communication purposes. This in turn relies on basic skills in information and communication technology (ICT) such as using computers to source, evaluate, store, produce, present and exchange information as well as to communicate and engage in collaborative networking via the Internet. With regard to collaboration, the document places strong emphasis on the relational dimension which in turn demands social competences. These are personal, interpersonal 
and intercultural competence and all forms of behaviour that equip individuals to participate in an effective and constructive way in social and working life, particularly in societies that are becoming increasingly diversified, and to resolve conflict when the need arises.

Initiative and Entrepreneurialism are included in the national guidelines in their own right and are defined as the ability to turn ideas into action. This involves creativity, innovation and risk-taking, as well as the ability to plan and manage projects in order to achieve objectives.

Assessing and analysing information, is partly reflected in the competences listed under learning to learn, that is to say, the ability to pursue and organise one's own learning, including effective management of time and information, either individually or in groups. This set of skills includes being able to acquire, process and assimilate new knowledge, as well as the ability to seek out and avail of opportunities for orientation. In addition, it encompasses awareness of one's own learning processes and needs, identification of learning opportunities and the capacity to overcome obstacles to successful learning. This last aspect is also related to the skills grouped under the heading of critical thinking and problem solving.

Critical Thinking and Problem Solving account for a part of the skills prescribed for the subject areas of mathematics and science. The document divides these areas into mathematical competence defined as the ability to develop and apply mathematical thinking in order to solve a range of problems in everyday situations, and competences in science understood as the mastery, use and application of knowledge and methodologies that explain the natural world in order to identify questions and draw evidencebased conclusions.

Finally, Curiosity and Imagination come under the heading of cultural awareness and expression, which has to do with the importance of the creative expression of ideas, experiences and emotions in a range of media, including music, performing arts, literature, and the visual arts.

As this analysis shows, the ministerial document calls for the development of many of the so-called twenty-first century skills. However, the short time lapse since the introduction of the new curriculum along with the difficulties inherent in effecting any educational change, mean that the document may not yet have had a significant impact on teaching practices in all Italian schools. On the other hand, the rising levels of cultural and linguistic diversity within class groups, the impact of information technology on teaching and learning processes, and the growing proportion of teachers with university training, lead us to suppose that there may be increasing awareness of the need to provide our future citizens with this broad skills base. Most especially, of the need to provide students with a training that enables them to activate and exploit their own resources - knowledge, abilities, attitudes, emotions - in order to successfully deal with the situations posed to them by daily life situations. 


\subsection{Twenty-First Century Skills in the Degree Course in Primary Education offered by Milan-Bicocca University}

The most recent educational measure concerning teacher training came into force in Italy with the Ministerial Decree n 249 of 2010, which states that "The five-year degree course in Primary Education promotes advanced theoretical and practical training in psycho-pedagogical, methodological, didactic, technological and research disciplines. It also provides specific training for the reception and inclusion of pupils with disabilities ${ }^{3 .}$."

The official curriculum of our own Degree Course expresses students' expected learning outcomes in terms of the Descriptors used in the European Qualifications Framework (DM 16/03/2007, Art. 3, Comma 7). These expected outcomes may be summarized as follows:

- Knowledge and understanding. By the end of their academic training, graduates must possess: in-depth knowledge of the field of educational science; knowledge and understanding of how to cater for students' needs and prevent learning difficulties; basic knowledge regarding pupils with disability and an understanding of how to care for their needs and provide personalized educational interventions; knowledge of information technology and of all the new technologies designed for use in the classroom.

- Applying knowledge and understanding. By the end of their academic training, graduates will have acquired: the capacity to create an authentic educational relationship; the capacity to identify and define educational priorities; the capacity to structure subject knowledge into teaching programmes; the capacity to generate a welcoming and inclusive atmosphere in class, that encourages the inclusion of pupils with disability, with learning difficulties or of different nationalities, cultures and religions; the capacity to design educational action drawing on a variety of methodologies; the capacity to document their work, monitor their educational interventions and provide suitable instruments for assessing student learning outcomes.

- Making judgements. By the end of their academic training, graduates must display the following aptitudes: awareness of the ethical and cultural responsibility associated with exercising the teaching profession; aptitude for interpreting students' needs and behaviours; aptitude for problematizing educational situations and events, analysing them in depth and reflecting about them; aptitude for taking into account alternative solutions to problems and making decisions in line with pupils' educational needs; aptitude for making judgements about educational situations

3 Note that in Italy, from 1974 onwards, all pupils with disabilities (including serious disabilities) have had the right to attend ordinary classes and schools (at every level of schooling). This is an unalienable right: it is a penal offence for a school to refuse to enrol a student with disability. The right to inclusion has also been extended to early childhood and university education (Art. 12, Law 104/92). 
and events; aptitude for valuing their own professional training and the effectiveness of their teaching methods; aptitude for adopting innovative teaching methods.

- Communication skills. By the end of their academic training, graduates must possess: the capacity to moderate verbal and non-verbal interaction in class; the ability to dialogue with colleagues at staff meetings; the ability to organize and present the objectives and nature of their teaching activities; the ability to clearly communicate learning outcomes and possible solutions for difficulties encountered to the pupils and their families, as well as to the other teachers; the capacity to establish a positive relationship with the pupils' families; the ability to use the digital communication tools available to schools. The acquisition of these learning outcomes is transversal to the entire degree programme.

- Learning skills. By the end of their academic training, graduates will have developed a set of learning abilities equipping them for lifelong learning: an interest in the teaching profession and the desire to advance their knowledge and improve their practice of it; aptitude for broadening their educational and methodological knowledge base; willingness to explore the perspectives of educational, methodological, technological and media research; aptitude for self-sustaining and self-regulating their own learning via independent bibliographical research and motivated participation in ongoing training programmes.

As this summary of the descriptors shows, while twenty-first century skills are not specifically mentioned in the outline degree programme they feature transversally in virtually all the descriptors. For example, Critical Thinking and Problem Solving may be identified within the descriptor on making independent judgements: similarly, Effective Oral and Written Communication is included in the communication skills descriptor.

\subsection{Twenty-first century skills in the words of key informants}

The final step in our analysis was to investigate the status of twenty-first century skills in educational practices (the course modules, workshops and teaching practice offered by our degree programme) by interviewing key informants (dean, head of the degree course, professors and students - both graduates and undergraduates). Our analysis of the interview transcripts enabled us to identify, for each of these skills, the relevant activities conducted with the students. These activities, reported below, provide us with a basis for initial reflection.

Concerning Critical Thinking and Problem Solving the entire approach of the degree programme is to stimulate independent and critical thinking. Students are frequently provided with opportunities to think for themselves. For example, during course modules, different perspectives and theories are presented, compared, and situated in their historical context and students are encouraged to explicitly express their own ideas and 
reflections about them. As the professors we interviewed pointed out, lessons rarely follow a traditional lecture-style format, but are an alternating sequence of explanations, dialogue and interaction, in the course of which the students are continuously being stimulated to expand their own knowledge base. The same is true of the learning materials chosen for the courses, in that they generally comprehend a range of authors and texts reflecting different viewpoints. With regard to assessment criteria, again we may state that the students are not asked to repeat contents without adding an element of personal opinion. Assessment make take a range of forms from open questions, to conceptual maps, to problem scenarios, to group assignments.

The use of critical thinking and problem scenarios features even more strongly in the workshops, independently of subject area, and the teaching practice supervision groups. Here, work on case studies, analysis of protocols and materials for children and teachers, role-play, and the use of active technologies allow students to learn by doing and to experience a continuous alternating of deductive and inductive thinking, as well as developing their capacity to relate to others and make decisions collaboratively. As one of our students stated: "This series of workshops has been very interesting: I had the opportunity to reflect upon and better understand the importance of verbal and non-verbal communication. I already had the chance to study this topic in my books, but having the opportunity to try it out first hand is a different experience. This Faculty is preparing us to become teachers and workshops like these help us to improve our knowledge."

During direct teaching practice, this skill is even more strongly required, initially mainly in the context of observation practices, and subsequently in the context of the trainee teacher's direct participation in class activities. As reflected in the words of one of our students during a teacher training placements "... we had the opportunity to grapple with the issues that teachers face on a daily basis. Like teachers, we addressed the needs, knowledge, specific needs of a particular class: we planned specific activities and materials to meet the needs of each individual student". Here too the students are required to deal with problem scenarios in a hands-on context, later having the opportunity to analyse and reflect on the experience in the setting of their indirect teaching practice group.

Regarding the skill Accessing and Analyzing Information we found that all the course modules make constant use of information sourced on Internet and by searching international databases. Students are taught to bring a critical approach to bear on these information searches and to explicitly report the search methods used for their research projects. Many courses are offered in an e-learning format, and many assess students' ability to make critical use of databases. Students have access to international databases, electronic journals and eBooks both at the University library and remotely from home or other locations. Ad hoc seminars have also been designed to help students learn how to carry out research on line for their practical or theoretical assignments. Support materials are also available on the University library website. Furthermore students can avail of personalized support from library staff when they 
need to carry out a particularly challenging information search. All of these activities are designed to encourage critical and competent use of the information collected.

Concerning the skill set Effective Oral and Written Communication, a series of initiatives have been undertaken in recent years. The indirect teaching practice component of the degree programme now includes a focus on the creation of a range of discursive genres (from PowerPoint presentations to the student's final report on each annual period of teaching practice) using collaborative writing approaches. Specifically, students are encouraged to collaborate on the planning and revising stages of each text that they produce, as exemplified in the following excerpt from an interview with a student: “... on more than one occasion we were required to reason amongst ourselves: during the planning phase we had many doubts, arising from our exchanges with other students and the supervisor (How should I shape my ideas? How can I be clear enough?)".

The use of digital media and environments to communicate and work collaboratively is also on the increase. For students with difficulty in writing, ad hoc workshops have been designed to provide individual guidance to enhance writing skills. As stated earlier, oral communication is fostered throughout the entire degree programme thanks to the dialogical and interactive mode of delivery of course and workshop contents, and is considered a vital competence for the defence of students' master's theses. The linguistic competence and conceptual clarity displayed by the final year student during the viva voce examination is viewed as an indispensable part of the skill set of a future teacher.

With regard to the Collaboration Across Networks and Leading by Influence area of competence, in addition to the digitally supported collaborative writing activities mentioned earlier, all course modules are provided with a shared platform. The structure and mode of use of this communicative resource depends on the ICT competence of individual professors. Consequently, the platforms range from highly interactive, with the facility for forums, question and answer pages, sharing of materials, and the collaborative construction of a variety of products, to an extremely limited use of this resource, for example to publish PowerPoint lesson notes. On their part, the students create their own shared spaces, such as Facebook and WhatsApp groups, in which to interact and exchange information (notes, advice, course information, etc.).

With regard to the skills under the heading Curiosity and Imagination, some courses, workshops and teaching practice periods are designed to strongly promote the exploration of spaces and materials (Smith, 2008), others the ability to design teaching programmes, others the use of video recordings and photography as a mode of research and planning (Goldman, 2009), and still others a variety of research techniques to stimulate new thinking and ideas - ultimately the students acquire awareness of the teaching profession as a complex occupation that requires constant intellectual curiosity and a good imagination. 
Finally, the skills Agility and Adaptability and Initiative and Entrepreneurialism, although transversal to the entire degree programme, were less tangibly described by the key informants. Certainly, the teaching practice component of their training progressively facilitates students in becoming more independent in developing, monitoring and evaluating teaching and learning programmes. Their teaching practice placements require them to display the capacity to adapt to a specific school environment, as well as a personal sense of initiative.

\section{Conclusion}

To conclude our study, after interviewing key informants from within the degree programme itself, we held a focus group discussion on the theme of twenty-first century skills with a group of teachers who are members of the VoiceS project. From the preliminary data collected by administering ${ }^{4}$ a questionnaire to 20 teachers and teaching practice supervisors, it emerged that in their teaching practice at school the competence most worked on with their pupils is Curiosity and Imagination, while that which they are least successful in stimulating is Collaboration across Networks and Problem Solving. In training the undergraduate students under their supervision, they reported that Critical Thinking and Problem Solving is the area of competence that they are most successful at fostering, while the two competences that they least manage to promote are Initiative and Entrepreneurialism, and Collaboration across Networks and Problem Solving.

\section{Final Reflections}

This preliminary analysis of the status of twenty-first century skills in training guidelines and programme outlines and in the actual training practices currently being implemented with future teachers brings to light some aspects that we believe will need to be addressed in the future. Our findings suggest that the set of skills included under the heading Initiative and Entrepreneurialism receives hardly any mention in the official documents and, even more importantly, does not seem to be taken into account in current educational practice at either the university or school levels. The second competence that clearly needs to receive more attention than at present is Collaboration across Networks and Problem Solving. Although the university is technologically well-equipped, the academic staff overall has yet to reach an optimum level of competence in using it and exploiting its potential to work together with diverse groups to facilitate the exchange of ideas to achieve a goal, make decisions, and solve problems.

4 The questionnaire was administered at the beginning of the project meeting held on $8^{\text {th }}$ Aprile 2015. 
In contrast, the university students themselves display the ability to generate results collaboratively across a variety of contexts without direct authority.

On the positive side, one of the most significant competences for the informants in our study was the capacity to engage in critical thinking. For both primary school and university-level teachers developing critical thinking represented a key value. A value that they view as "non-negotiable", as one of the university professors explained "...we like to think of a teacher that asks questions, promotes reflection and exchange, that invites [pupils] to look for possible alternatives, new pathways, in other words a critical and reflective teacher."

Looking to the future, given the limits of the present study, we believe that it will be necessary to carry out an analysis of teaching practices directly in schools with a view to assessing whether and how they foster twenty-first century skills. An investigation that would shed light on exactly what is happening inside classrooms. Data sources might include ethnographic observation and documentation produced by the students themselves. Such a study may be facilitated and carried out by the research group of supervisors and infant, primary and secondary school teachers that is an offshoot of Voices, and that will provide us with the opportunity to explore in depth the relationship between twenty-first century skills and teacher practices. The current study, meanwhile, has pointed up the value of a range of existing practices, thematising and stimulates focused reflection on them, as well as highlighting the steps that still need to be taken. It is important that these results be disseminated in order to provide a common ground for reflection going forward.

\section{References}

AAVV, (2012). Indicazioni nazionali per il curricolo della scuola dell'infanzia e del primo ciclo d'istruzione (National Guidelines for the Curriculum of Infant School and Primary Education).

Bassey, M. (1999). Case Study Research in educational settings. Buckingham: Open University Press. Bryman, A. (2004). Social Research Methods. Second edition. Oxford: Oxford University Press.

Goldman, R.; Pea, R.; Barron, B. \& Derry, S. Eds. (2009). Video ricerca in contesti di apprendimento. Milano: Cortina (Video Research in the Learning Sciences, Lawrence Erlbaum Associates, 2007).

La Neve, C. \& Pascolini, F. Eds., (2014). Nella Terra di Mezzo: Una ricerca sui Supervisori del Tirocinio. Brescia: Editrice La Scuola.

Schön, D. A. (2006). Formare il professionista riflessivo: per una nuova prospettiva della formazione e dell'apprendimento nelle professioni. Milano: Franco Angeli. (Educating the reflective practitioner: Toward a new design for teaching and learning in the professions, 1987).

Stake, R. (1995). The Art of Case Study Research. Thousand Oaks, CA: Sage Publications

Mayring, Ph. (2002). "Qualitative content analysis - research instrument or mode of interpretation?" In M. Kiegelmann (Ed.), The role of the researcher in qualitative psychology (pp. 139-148). Tübingen: Verlag Ingeborg Huber.

Smith, K. (2008). Come diventare un esploratore del mondo. Milano: Corraini (How to be an explorer of the world). 
Teruggi, L. \& Bettinelli, G. (2010). "La sfida della coerenza tra formazione e ricerca”. In Kanizsa, S. \& Gelati, M.(eds.) 10 anni dell'Università dei maestri (pp.82-92). Bergamo: Ed. Junior.

Varani, A. (2014). Osservazione e riflessione. I laboratori dei Supervisori. In C. La Neve, \& F. Pascolini (Eds.). Nella Terra di Mezzo: Una ricerca sui Supervisori del Tirocinio (pp.173-188). Brescia: Editrice La Scuola.

Yin, R. (2009). Case Study Research: Design and Methods, fourth edition, Thousand Oaks, CA: Sage Publications.

\section{Acknowledgement}

The Article is dedicated to Project The VOICE of European TeacherS (VOICES), 526613-LLP2012-NL-Comenius-CNW.

\section{Contact:}

Lilia Andrea Teruggi, Franca Zuccoli

Università degli Studi Milano-Bicocca

Dipartimento di Scienze Umane per la Formazione "R. Massa"

Via Thomas Mann 8

20126 Milano

Italy

E-mail: franca.zuccoli@unimib.it; lilia.teruggi@unimib.it 